\title{
Uma reflexão sobre tolerância e subjetivação à luz de Nietzsche ${ }^{1}$
}

\author{
Thoughts on toleration and subjectivation \\ in the light of Nietzsche
}

\section{Olímpio José Pimenta Neto}

Doutor em Estudos Literários pela Universidade Federal de Minas Gerais (UFMG), pós-doutor em Filosofia pelo Instituto de Filosofia e Ciências Sociais da Universidade Federal do Rio de Janeiro (UFRJ), docente na Universidade Federal de Ouro Preto (UFOP), Ouro Preto, MG Brasil, e-mail: olimpix@ig.com.br

\section{Resumo}

Este escrito consiste na elaboração filosófica pessoal de algumas experiências difíceis. A partir de um debate acadêmico sobre matéria de interesse coletivo, fomos instados a pensar nas condições mais ou menos propícias para a criação de um ambiente no qual poderia prevalecer a prática da

Com algumas modificações, trata-se do texto que serviu de base para minha comunicação nos XXIX Encontros Nietzsche, ocasião de ótimos convívio e conversas com Scarlett Marton, Chiara Piazzesi, Diego Sanchez Meca e Luis Enrique Santiago Guervós, pacientes colegas a quem ofereço o artigo 
tolerância. Impôs-se articular o tema à questão da formação das subjetividades fomentada no departamento de filosofia a que pertencemos. Uma circunstância estranha: apesar da escassa ocorrência nominal desses assuntos em Nietzsche, optamos por referenciar a reflexão ao seu pensamento, assumindo a tarefa como uma tentativa ou, em sentido preciso, como um ensaio.

Palavras-chave: Tolerância. Subjetivação. Subjetividade. Nietzsche.

\section{Abstract}

This writing consists in a personal philosophical elaboration of some difficult experiences. Departing from an academic debate on an issue of common interest, we were called to think about the more or less favorable conditions to upbring an environment in wich the practice of tolerance could prevail. It was further required from us to articulate this point to the matter of wich is the pattern of development of subjectivities that works in our department. An odd feature: inspite of the few nominal references to these subjects in Nietzsche, we chose to connect our reflexion to his thought, adopting our task as a tentative or, in precise sense, as an essay.

Keywords: Toleration. Subjectivation. Subjectivity. Nietzsche.

\section{Introdução}

Ao tratar das relações entre paganismo e cristianismo no tempo do imperador Constantino ${ }^{2}$, o sempre brilhante Paul Veyne (2010) traça um quadro muito claro distinguindo os motivos que podem conduzir os homens à prática da tolerância. É referida, em primeiro lugar, a tolerância ou como consequência do agnosticismo ou como efeito da convicção de que muitos caminhos podem levar à verdade. Segue-se aquela obtida em função de um compromisso entre facções irreconciliáveis para pôr fim a guerras e perseguições, e por último a modalidade que estipula formalmente a separação

\footnotetext{
2 Ver VEYNE, P. Quando nosso mundo se tornou cristão. Rio de Janeiro: Civilização Brasileira, 2010.
} 
entre âmbitos nos quais circulam as crenças - por exemplo, distinguindo o Estado das várias confissões que coexistem em seu interior. $\mathrm{O}$ caso que vou discutir pode ser vinculado a uma dentre essas acepções, conforme se pretende estabelecer ao fim. Entretanto, para evitar mal-entendidos terminológicos, devo dizer de saída que, para nossos fins, o conceito em questão significa, principalmente, disposição para desdobrar os conflitos, e não para fazê-los cessar - isto é, estamos tomando os conceitos e práticas ligados à tolerância como ocasião para desenvolvimento das diferenças, e não para sua superação.

A questão começou a se delinear há alguns meses, quando se promoveu no departamento de filosofia a que pertenço um debate a respeito dos usos do tabaco ${ }^{3}$. Ocorreu então comigo, chamado a participar, aquela proverbial mudança de perspectiva que os interlocutores de Sócrates nos diálogos platônicos são sempre instados a fazer. Partindo de um problema concreto, para o qual era solicitada uma solução prática, o desenvolvimento do simples jogo de opiniões mostrou-se insuficiente. Notou-se que as tais opiniões eram como que reflexos apenas sintomáticos de outras tantas tomadas de partido a respeito de questões anteriores. Na condição de leitor de Nietzsche, percebi que o bastidor valorativo e vital no qual as posições em debate se inscreviam exigia uma exploração mais atenta. Ultrapassamos nessa altura o proveito da inspiração socrática: cumpria prosseguir numa direção diferente da que o ateniense tomou, buscando não o universal subjacente às varias opiniões, mas as próprias motivações que alimentavam cada uma delas, emprestando-lhes sua força e eventual coerência.

Sem nos determos ainda na explicitação dos argumentos sobre a regulamentação dos direitos dos tabagistas e dos não tabagistas nas dependências do instituto, interessa reportar o que pode ser chamado de parte oculta dos icebergs em rota de colisão - ou, das posições tolerante e intolerante, de início associadas a como e a o que se pode fumar ali. O que aconteceu foi que a divergência sobre saúde, hábitos de consumo e legislação vigente rapidamente se transferiu para um conflito a respeito da metodologia a ser admitida na investigação em curso. Não houve entendimento sobre o que estimar como o mérito racional de um discurso, instalando-se um impasse. É claro que, havendo impasse quanto a isso,

O âmbito do debate foi o projeto de iniciação científica "Ágora”, orientado pela colega Imaculada Kangussu, cuja dinâmica básica consiste na realização de conversas com alcance filosófico sobre temas variados, sempre abertas ao público em geral. A meu ver, trata-se de uma das atividades mais importantes em andamento no IFAC.

Estudos Nietzsche, Curitiba, v. 2, n. 2, p. 207-217, jul./dez. 2011 
não seria possível avançar - a não ser que se promovesse, outra vez, uma transferência do âmbito do debate. Ao invés de procurarmos estabelecer, em abstrato, regras prévias para a conversação, a saída seria indagar sobre as motivações dos grupos proponentes das posições em confronto, como mencionado anteriormente. Em qual delas encontraríamos uma genuína disposição para convencer e se deixar convencer, evidência da presença de uma consciência intelectual efetiva, elemento decisivo para a emergência de uma transformação real nos desejos dos participantes da conversação? ${ }^{4}$

Antes de contarmos como se desenrolou a história, é hora de chamar à baila algumas ponderações sobre o que Nietzsche ensina serem as condições mais propícias para a instalação de práticas de convivência imbuídas de tolerância - que, como se verá, favorecem também, por vias oblíquas, o surgimento de determinadas tiranias. O livro um de A gaia ciência, por meio de uma intrincada articulação entre reflexões sobre o devir histórico da moral, da cultura e das mentalidades, exibe uma galeria de tipos e cenários que se prestam bastante bem à condução do assunto. Ao nos determos no aforismo 5 - "Deveres incondicionais" - e também no grupo que vai do 21 ao 23 - cujos títulos respectivos são "Aos mestres do desinteresse", "A ordem do dia para o rei" e "Os sinais da corrupção" — encontramos um complexo de considerações que define atmosfera, clima e solo favoráveis à eclosão de homens e comunidades inclinados, tanto à tolerância quanto a seu negativo, o par tirania-obediência. O que poderia à primeira vista parecer incongruente é elucidado com finura pelo filósofo, conforme as linhas gerais que se seguem.

O surgimento dos conceitos em estudo, bem como das práticas que lhes correspondem, tem como condição necessária um ambiente marcado pela promoção do esclarecimento moral e intelectual. Uma época que acolhe valores assim, afins do ceticismo e da abertura de espírito, vive um afrouxamento dos ditames da moralidade do costume, o que faculta a ampliação dos domínios da individualidade e das várias modalidades do cultivo de si. A arena dos principais antagonismos não é a cena política aberta, mas um espaço público bastante instanciado, no interior do qual é possível defender posturas vinculadas ao atendimento de predileções pessoais. Trata-se, decerto, de uma circunstância ambígua. Por um lado, vive-se a chance de dar estilo

\footnotetext{
4 Ver, a esse respeito, o notável aforismo 2 de A gaia ciência, exatamente intitulado "A consciência intelectual".

5 NIETZSCHE, F. A gaia ciência. São Paulo: Schwarcz, 2001.
} 
a um caráter, o que favorece a tolerância, enquanto arte da aproximação - a disposição para escutar tudo o que é dito de maneira equânime - e do distanciamento - resultado do ajuizamento que conclui que nem tudo o que é dito importa, e que nem todo mundo tem o que dizer. Um sem-número de paixões tem ocasião de se configurar através de uma expressão justa, mas tal realização é muito menos freqüente do que suas tentativas.

Por outro lado, essa deriva, em que é permitido que todos se manifestem, mas na qual quase nenhuma produção alcança alto grau de qualidade - coisa dura em relação às ambições da maioria -, tende a aborrecer os mais impacientes, sugerindo-lhes atitudes extremadas. A mais comum é a imposição de algum imperativo de última ordem para regulamentar, à força, a proliferação de discursos e experiências. Um exemplo disso é a iniciativa de tornar obrigatória a aferição do valor dos discursos com base exclusiva na correção e na integridade de sua estrutura proposicional - sinal claro de uma vontade abusiva de simplificar o que é naturalmente complexo nas relações humanas.

O quadro comporta, então, dois polos contrapostos, radicados em um mesmo estado de coisas. Dado o amplo espaço disponível para o florescimento das diferenças, haverá aqueles dispostos a aproveitar o ar do tempo em que vivem investindo sua energia em projetos e vivências variados, sem esperar que decorra daí a construção de uma subjetividade sólida e definitivamente fixada. Entre eles e seus preferidos prevalecerá a indeterminação quanto ao conteúdo do conceito do que é bom, naturalmente ligada a outra indeterminação, relativa à questão sobre quem se é. Uma coisa, entretanto, funciona para esses como referência permanente: a prática do respeito aos caminhos de cada um no que concerne à pesquisa da verdade, indissociável de algo como o cultivo de $\mathrm{si}^{6}$. Vale acrescentar que os limites para sua ação dependem do bom senso compartilhado. Diretrizes como o respeito ao corpo, à opinião, à propriedade e à vida do vizinho são elementares em períodos de esclarecimento, conforme ditado por nossa premissa histórica. Em caso de não se saber se se está atendendo ao que sugerem as diretrizes assinaladas - afinal, uns fumam e outros não - a arbitragem deve se ocupar com a distribuição de fronteiras e não com a oferta de provas definitivas sobre o que quer que seja.

${ }^{6}$ Sobre isto, e também sobre o amor de si ver, por exemplo, a seção II, 9 de NIETZSCHE, F. Ecce Homo. São Paulo: Schwarcz, 2004. 
O contraponto aos tolerantes vem de uns tipicamente ansiosos, que arrogam a si o conhecimento dos critérios para discernir o certo do errado e o bem do mal. A análise de Nietzsche a seu respeito propõe que,

por quererem que se tenha absoluta confiança neles, necessitam antes confiar absolutamente em si mesmos, com base em algum derradeiro e indiscutível mandamento, inerentemente sublime, do qual gostariam de sentir-se e aparecer como servidores e instrumentos (GC I, p. 5).

Lembremos que tais adeptos dos "deveres incondicionais" surgem para o pensador no mesmo terreno em que aparecem seus antagonistas, os adeptos da tolerância. Todavia, o declínio da autoridade da tradição é apreciado por eles de maneira completamente diversa. Não aceitam que o jogo dos afetos, matriz das avaliações com que os viventes lidam, instituindo suas formas efetivas de viver, está em contínua transformação, no seio da qual não há meio de se definir regras que valham acima do próprio jogo. Segundo a perspectiva de grupos com tais características, apenas a força cogente de princípios inequívocos é capaz de incorporar o principal: uma fé arrancada à vertigem da dúvida, fundamento de sua iniciativa de sujeição de todos às suas medidas 7 .

A nota dominante na subjetividade desses últimos é, pois, a insatisfação com uma condição existencial destituída de um sentido totalizante. A ausência de justificativas finais para nossa situação no mundo é sentida como circunstância intolerável, que precisa ser remediada a qualquer custo. Sua inclinação à tirania mostra, enfim, de que é feita: não é força o que a constitui, mas fraqueza. Quando condenam a corrupção de seu tempo - tratada por Nietzsche como a época outonal de um povo, hora em que este colhe seus frutos finalmente maduros - no fundo se dirigem aos instintos da maioria, que se acham desordenados e exaustos. Com efeito, alguma higiene pode vir daí: uma bandeira qualquer tende sempre a motivar os menos firmes, dotando-lhes de disciplina e propósito. Mas é sabido, também, que metas heterônomas duram enquanto dura a hegemonia de quem as impôs, e higiene definitivamente não é saúde, ao menos no sentido preconizado por Nietzsche.

Uma série de desdobramentos permite refinar o contraste entre os tipos esboçados. O sujeito que prefere a submissão à primeira autoridade que

\footnotetext{
7 Para efeito de contraste, vale referir novamente algo do Ecce Homo: "Aí não fala um fanático, aí não se 'prega', aí não se exige fé" (Prólogo, 4).
}

Estudos Nietzsche, Curitiba, v. 2, n. 2, p. 207-217, jul./dez. 2011 
triunfa, ao invés de contribuir para a qualificação dos candidatos a assumir o posto, recebe a contrapartida imediata de um reforço em sua confiança. Sente a servidão como uma vantagem em função do apaziguamento que passa a vigir após a imposição de limites para a ação e a expressão gerais. O problema é que ele ignora o caráter postiço da intervenção, bem como seu efeito alienante. Não se obtém assim um estado de coisas justo, mas apenas funcional, no que isso tem de menos legítimo. É claro que se pode alegar, sob orientações pragmáticas variadas, que uma ordem qualquer é preferível a ordem nenhuma. Ora, isso seria admissível em confronto com a violência pura, mas reiteramos não ser esse o caso nos ambientes aos quais remete a presente reflexão. $\mathrm{O}$ fantasma da ausência da lei e do direito é o que alimenta, em última análise, aquele elogio da obediência, com o que encontramos sua raiz secreta no medo e em sua administração pelo tirano, e não na coragem própria da confiança.

Apesar dessa deficiência estrutural, o súdito voluntário do tirano pode prosseguir imaginando que está no melhor dos mundos, pois outros efeitos contribuem para a manutenção de seu autoengano. Uma vasta gama de perguntas permitidas antes de sua conversão é agora interditada. Não há mais motivo para ele se dispor a enfrentá-las, pois as regras sobre purificação discursiva já definiram que o que vale é só e exclusivamente o que admite tratamento proposicional formalizado - inclusive no que tange à moral! Duas consequências especialmente esquisitas saem daí: a ilusão de que se está, enfim, numa época de progresso epistêmico - pois há mesmo grande volume de resultados positivos a se acumular - aliada à ilusão de que se sabe, à revelia da historicidade, o que é a verdade para o pensamento. A mais lamentável soberba intelectual se nutre disso: os menos afeitos ao debate imaginam-se os mais proficientes nele, os ignorantes acham-se cheios de ciência, a fraqueza aprece travestida em vigor, numa autêntica transvaloração de cabeça para baixo.

No campo contrário encontramos o predomínio de outras disposições. À primeira vista, a manutenção da abertura de espírito parece fragilizar quem milita a seu favor, pois não lhe empresta uma identidade facilmente reconhecível nem pontos de vista cristalizados. Se, por princípio, tudo pode ser objeto de discussão, e o próprio andamento de cada debate varia de acordo com as contingências do momento, talvez pareça sensato considerar que é perda de tempo prosseguir nesse caminho. Ora, se a via da verdade, à moda de Parmênides, tivesse sido definitivamente estipulada, a 
objeção faria todo sentido. Acontece que essa pretensão é também alvo de controvérsia, restando como única atitude propriamente honesta a permanência no agnosticismo. No melhor dos casos, os participantes dessa forma de vida estarão aptos a conceder primazia à posição mais conveniente para cada situação - entendendo-se conveniência, mais uma vez, em termos de bom convívio e respeito pela diferença.

Cabe agora retomar o ponto de onde partimos, a fim de cotejar a exposição precedente com um experimento exemplar. A pergunta "É proibido fumar?" consistia no mote do diálogo, cujo começo mostrou-se promissor, graças a um acordo de base sobre duas premissas de fato. Ficaram estabelecidos como postulados que o cigarro faz mal para a saúde, mas que, mesmo assim, sua produção, comercialização e consumo devem permanecer na legalidade. A contradição que demandava nossa tentativa de esclarecimento foi, dessa maneira, posta em evidência.

Algumas digressões iniciais, bastante parecidas com aquelas reputadas como simples doxa na fase preliminar de um diálogo aporético, abriram a disputa, podendo ser resumidas como se segue. Contra os que defendiam a geração de emprego e renda associados ao tabaco, foi proposta uma substituição na atividade econômica do produtor. Quanto aos que defendiam o hábito do consumo do tabaco apelando para o prazer e o glamour que lhe são inerentes, objetou-se que o senso comum atualmente identifica o fumante como um pária, um drogado incontinente, que merece inclusive o ataque da milícia das crianças, devidamente instruídas por campanhas publicitárias de conscientização - restando averiguar se a associação entre "propaganda" e "consciência" não é um contrassenso. De outra parte, contra os que denunciavam que o interesse das seguradoras e dos planos de saúde é o motivo real da eliminação paulatina dos fumantes, alegou-se que é a ciência quem detém a verdade sobre o tema. Quando seus porta-vozes se manifestam com conhecimento de causa, suas instruções devem ser seguidas, e não avaliadas. Estatísticas não mentem e o seguro tem função mais nobre a desempenhar do que cuidar de quem decide fazer o mal a si e aos outros, que afinal deveria arcar com as consequências de seus pecados por conta própria.

Alguém sugeriu que essa escaramuça inconclusiva poderia ser resolvida de maneira plebiscitária. Entretanto, a definição da natureza da comunidade na qual ela se desenrolava excluiu tal encaminhamento: o mínimo de intimidade com a filosofia faz saber que o maior número e o melhor 
argumento não andam necessariamente juntos. Restava-nos pensar sobre os valores a serem compartilhados ali, isto é, cumpria redirecionar a investigação, passando a refletir sobre o que poderia conferir dignidade a nossa convivência coletiva, chancelando sua razoabilidade e confirmando ser ela desejável. Pela primeira vez, foi invocada a tolerância, valor central para a promoção de uma determinada concepção da vida boa - aquela que defende o desenvolvimento das diferenças como condição para que cada um se forme como indivíduo autárquico. A seu favor foi lembrado que uma meta assim anda junto da vida filosófica desde que essa despontou há 25 séculos.

Nesse momento se anunciou uma dificuldade crucial para o avanço da discussão. Independentemente da existência da tradição assinalada, alguns interlocutores fecharam questão sobre o seguinte: para se credenciar ao debate, cumpria que qualquer alegação assegurasse para si viabilidade teórica, e mais nada. Nesse sentido, enunciaram suas objeções: primeiro, tolerância gera conformismo, pois se tudo vale, tudo fica como está; depois, enquanto valor universal, tolerânciaimplica a aceitação da intolerância, pois permitirtudo implica permitir a presença de quem não quer nada além de seus próprios preconceitos.

Ainda num plano estritamente teórico, replicou-se que, ao contrário do que fôra dito em primeiro lugar, tolerância implica engajamento, convocando a tudo, menos ao conformismo. Cumpre haver reconhecimento efetivo da diferença para que se fale que ela é tolerada, pois senão sequer se entrou em relação com ela. A atitude em causa está constitutivamente ligada à ação, e não somente à especulação, de modo que a condição pretendida - circunscrever o debate ao domínio da teoria - significaria a interdição da questão de mérito, anulando o interesse do próprio debate.

Sendo assim, o caminho para a percepção de que não estávamos às voltas com a discussão de um valor universal abstrato foi consolidado - pelo menos para o bom entendedor. Ocupávamo-nos com uma prática cotidiana, formada a partir da expectativa de reciprocidade, dependente do atendimento de determinadas condições efetivas. A adesão a um modo de vida chancelado pela deliberação em comum é o que verifica a realização ou não do valor que se queria afirmar. Não bastaria a admissão formal de um ordenamento que acolhesse a tolerância - isso, sim, geraria conformismo -, mas seria necessário praticá-la, do que decorre que ela só funcionaria entre pares engajados. Afinal, valores não são meras regras.

A raiz da dissensão pôde, por fim, ser exposta. O partido da neutralidade metodológica e do genuíno (des)interesse cognitivo declarou 
então sua fé: uma coisa é a realidade dos conceitos, outra os movimentos da existência. A verdade não depende de ninguém, não é uma noção humana, e sua pesquisa pura é ao que de mais elevado se pode aspirar. A ascese em direção ao discurso livre de toda injunção contextual é um dever para o grupo, que deve seguir a liderança daqueles que já sabem o que é e o que não é filosoficamente pertinente.

Nessa altura, o recurso a um dos aforismos referidos oferece algum alívio: "O louvor do desinteressado, abnegado, virtuoso [...] não nasceu do espírito de desinteresse! O 'próximo' louva o desinteresse porque dele retira vantagens!” (GC I, p. 22). No caso em pauta: vantagens inerentes ao alistamento de uma militância disposta a sacrifícios pela causa, à partidarização do ensino e aprendizado da filosofia, com o consequente aparelhamento das instâncias acadêmicas de representação, à transformação de estudantes em discípulos, com seu inseparável pressuposto, o culto à personalidade de professores comuns elevados à posição de guias iluminados. Todos inimigos da tolerância, mestres e seguidores de dogmas. Só esperam que os demais os respeitem - o que quer dizer: acatem suas definições, submetam seu discurso à jurisdição de sua lógica, concedam legitimidade irrestrita às suas preocupações especulativas e, em suma, tornem-se iguais a eles.

Diante disso, ficamos mais uma vez inclinados a saudar a inteligência do filósofo Nietzsche. Novamente se mostrou oportuno considerar aquela que pode ser sua principal sugestão no que concerne à tópica filosófica clássica. Seguimos amigos da verdade, continuamos comprometidos com o dever moral de examinar a fundo a moralidade, mas estamos à vontade com uma pergunta que não fazia sentido em outras épocas. Trocamos o "quê?", desde sempre envolvido por uma atmosfera metafísica, pelo "quem?”, que lança a indagação de ordem genealógica, e com isso temos mar aberto pela frente. Em nome disso, vale efetuar uma comparação entre os interesses que foram mencionados há pouco e os nossos próprios, o que também confirmará a quais tipos de subjetividade a tolerância e a tirania remetem.

Duas perguntas demarcam as margens da questão. Gostaríamos de saber o que significa separar o pensamento da vida, e também para quem isso é necessário. Quanto à primeira, pressentimos uma demanda extremada por segurança, compatível com uma vida declinante. A recusa do mundo, a náusea em relação ao que devém, sinalizam a ansiedade por um além estável, ligado a alguma forma de completude. Sistemas fechados, habitados por entes aptos a receber tratamento mecânico rigoroso, regras 
invariáveis para inferências com validade sempre calculável, alegações dotadas de potencial demonstrativo acima de disputa - toda essa parafernália para pensar parece-nos se contrapor ao que não tem descanso, ao que se move e se multiplica, ao jogo de criação e destruição próprios de um universo em expansão. Seu fundo é, portanto, mórbido. Em compensação, aproximar vida e pensamento parece um convite ao mais difícil dos exercícios, que é o desempenho da autonomia em um lugar perigoso, no qual nada há de absoluto ou assegurado. Precisa-se aí de conceitos capazes de acompanhar o movimento da experiência. Apenas a conquista de si, obtida por meio de uma composição continuada entre os impulsos mais pessoais e as demandas do meio, faculta o prazer em enfrentar semelhantes desafios. Que cada qual se dedique a se tornar quem é, alcançando nisso resposta para a segunda pergunta.

Sobre os usos do cigarro? A sabedoria da arquitetura colonial portuguesa proveu os prédios do centro de Ouro Preto com pátios internos arejados e jardins muito aprazíveis. As janelas amplas, o pé direito alto e a prática hegemônica da tolerância cuidam do resto.

\section{Referências}

NIETZSCHE, F. A Gaia ciência. São Paulo: Schwarcz, 2001.

NIETZSCHE, F. Ecce homo. São Paulo: Schwarcz, 2004.

VEYNE, P. Quando nosso mundo se tornou cristão. Rio de Janeiro: Civilização Brasileira: 2010.

Recebido: 27/04/2012

Received: 04/27/2012

Aprovado: 30/05/2012

Approved: 05/30/2012 